\title{
Tradeoffs Among Social, Resource, and Management Attributes of the Denali Wilderness Experience: A Contextual Approach to Normative Research
}

\author{
STEVEN R. LAWSON \\ ROBERT E. MANNING \\ School of Natural Resources \\ University of Vermont \\ Burlington, VT, USA
}

\begin{abstract}
Wilderness experiences are thought to be comprised of three primary dimensions, including social, resource, and management conditions. Decisions about how to manage wilderness recreation in Denali National Park and Preserve involve potential tradeoffs among these conditions. This study extends the normative approach to wilderness research by developing and applying a decision-making model that considers social, resource, and managerial attributes of the wilderness experience within a more holistic context. Specifically, stated choice analysis is used to evaluate the choices overnight wilderness visitors make when faced with hypothetical tradeoffs among the conditions of social, resource, and management attributes of the Denali wilderness. Study findings offer normative, but contextually informed empirical guidance in formulating indicators and standards of quality for the wilderness experience.
\end{abstract}

Keywords norms, indicators of quality, standards of quality, wilderness management, stated choice analysis, Denali National Park and Preserve

There is general agreement in the recreation literature that wilderness experiences are comprised of or defined by three dimensions, including the social conditions experienced (e.g., the number of other groups encountered), the resource conditions experienced (e.g., the amount of human impact at camping sites), and the management conditions imposed (e.g., the number of backcountry permits issued) (Hendee, Stankey, \& Lucas, 1990). In general, wilderness recreationists are thought to prefer a wilderness experience characterized as having few encounters with other groups, a pristine natural environment, and a high degree

Received 25 May 2001; accepted 17 September 2001.

Appreciation is expressed to Darryll Johnson and Mark Vande Kamp of the University of Washington for their help with the larger research project at Denali National Park and Preserve of which this study was a part. Park staff, especially Mike Tranel and Joe van Horn, were very helpful in designing and administering the study questionnaire. Don Anderson of StatDesign Consulting, Evergreen, Colorado, constructed the orthogonal fractional factorial design used in this study. Don Dennis of the United States Forest Service, Daniel Krymkowski of the University of Vermont, and Stephen Swallow of the University of Rhode Island assisted with the design of the study questionnaire and interpretation of the study results. Finally, this study was conducted under the auspices of the National Park Service's Conservation Study Institute housed at Marsh-Billings-Rockefeller National Historical Park. Appreciation is also expressed to Nora Mitchell, Rolf Diamant, B.J. Dunn, and Mea Arego for their administrative support.

Address correspondence to Steven R. Lawson, School of Natural Resources, University of Vermont, Burlington 05405, VT, USA. E-mail: slawson@ nature.snr.uvm.ed u 
of freedom from management control. While this is the ideal, attempts on the part of managers to provide ideal conditions along one dimension of the wilderness experience typically involve having to make concessions along one or both of the other dimensions of the wilderness experience. As a result, decisions about how to manage wilderness involve potential tradeoffs among the conditions of social, resource, and managerial attributes of the wilderness experience. For example, the number of permits issued for recreational use of a wilderness area could be increased to allow more public access, but this might result in more resource impacts and encounters among groups within the wilderness area. Conversely, reducing the number of recreational use permits issued might reduce resource impacts and encounters among groups, but would allow fewer people to enjoy the wilderness area.

The normative approach to recreation research has been used to study an expanding range of outdoor recreation and wilderness management attributes, including crowding (Hall \& Shelby, 1996; Manning, Lime, Freimund, \& Pitt, 1996; Williams, Roggenbuck, \& Bange, 1991), ecological impacts (Manning, Lime, \& Hof, 1996; Shelby, Vaske, \& Harris, 1988), and management practices (Shelby \& Whittaker, 1990; Vaske \& Donnelly, 1988). A fundamental element of the normative approach to recreation research is its potential application to selection of indicators of quality and formulation of standards of quality for such indicator variables. Traditionally, studies designed to assist wilderness managers in selecting or prioritizing indicators of quality have asked respondents to rate the importance of a series of wilderness setting attributes that are thought to be related to the quality of the wilderness experience (Roggenbuck, Williams, \& Watson, 1993; Whittaker, 1992). While this approach provides managers with useful information about the importance of various attributes of the wilderness experience, it does not necessarily provide managers with information about the relative importance of the attributes being evaluated. This approach does not reflect the tradeoffs inherent in wilderness management in that it does not constrain respondents from simply rating all competing or offsetting attributes as highly and equally important. Further, studies designed to inform wilderness managers' judgements concerning the formulation of standards of quality have traditionally focused on a single dimension or attribute of the wilderness experience, without explicit consideration of related and potentially competing issues associated with other dimensions or attributes of the wilderness experience (Manning, 1999a). Recent studies in outdoor recreation have suggested that normative research should more explicitly consider the tradeoffs inherent in park and wilderness management decision-making (Hall, in press; Lawson \& Manning, 2000a, 2000b, 2001; Manning, Valliere, Wang, \& Jacobi, 1999).

Our study expands the normative approach to wilderness research by developing a decision-making model that considers social, resource, and managerial attributes of the wilderness experience from a more contextual or holistic perspective. Specifically, stated choice analysis is used to evaluate the choices overnight wilderness visitors in Denali National Park and Preserve make when faced with hypothetical tradeoffs among the conditions of selected social, resource, and management attributes of the wilderness portion of the park. By making the tradeoffs associated with Denali wilderness management explicit to respondents, this study strengthens the tie between the normative methods to recreation research and normative theory. That is, this study measures what respondents think ought to be managed for given the relationships among the attributes of the Denali wilderness experience, whereas conventional normative methods may be measuring how visitors would prefer a single attribute of the wilderness experience to be managed, irrespective of its relationship to the conditions of other attributes. 


\section{Denali National Park and Preserve}

Alaska's first National Park, Mt. McKinley National Park, was established in 1917. In 1980, with the passage of the Alaska National Interest Lands Conservation Act, the park was expanded from two million acres to six million acres, and renamed Denali National Park and Preserve. At the same time, most of the original two million acres of the park was designated wilderness. Today, this two million acre wilderness forms the core of Denali National Park and Preserve.

Visitor use of the Denali wilderness is managed through a permit system to maintain the area's primitive, undeveloped character. Through the permit system, the Park administers strict quotas on the number of overnight visitors issued a permit for each of 43 wilderness management units. The quotas exist to control resource degradation and to provide visitors with opportunities to experience solitude. During the busy summer months, quotas for many of the management units are regularly reached and some visitors interested in an overnight trip in the Denali wilderness are turned away or forced to hike and camp in less preferred management units.

The primitive character of Denali's wilderness is maintained through other management techniques as well. For example, traditional backcountry facilities such as trails and bridges are not provided. Instead, visitors must navigate by map and compass, and visitors are frequently challenged with technical stream-crossings. There are no established campsites in the Denali wilderness, either. Visitors may camp anywhere within the management unit for which they were issued an overnight permit. As a result, visitors are often able to camp out of sight and sound of other groups, in places with little or no evidence of previous human use.

Park managers and planners are currently formulating a new wilderness management plan for Denali. Revision of the wilderness management plan will include making decisions to maintain, reduce, or increase the number of permits issued for each of the Denali wilderness management units. Previous research conducted by Bultena, Albrecht, and Womble (1981) studied the extent to which wilderness visitors in Denali supported use limitations. This study concluded that future decisions concerning use limitations in Denali will have to weigh the importance of protecting park resources and the quality of visitors' experiences against the benefit of granting more visitors access to the Denali wilderness. Our study uses stated choice analysis to provide park managers with information about overnight wilderness visitors' choices regarding such tradeoffs.

\section{Stated Choice Analysis}

Stated choice analysis models have been developed in the fields of psychometrics, econometrics, and consumer marketing to evaluate public preferences or attitudes (Green \& Srinivasan, 1978). ${ }^{1}$ In stated choice analysis, respondents are asked to make choices among alternative configurations of a multi-attribute good (Louviere \& Timmermans, 1990a). Each alternative configuration is called a profile, and is defined by varying levels of selected attributes of the good (Mackenzie, 1993). For example, respondents may be asked to choose between alternative recreation settings that vary in the number of other groups encountered, the quality of the natural environment, and the intensity of management regulations imposed on visitors. Respondents' choices among the alternatives are evaluated to estimate the relative importance of each attribute to the overall utility derived from the recreational setting. Further, stated choice analysis models are used to estimate public preferences or support for alternative combinations of the attribute levels (Dennis, 1998). ${ }^{2}$ 
Stated choice analysis has been applied to study public preferences concerning a range of recreation-related issues. Louviere and Timmermans (1990a) suggest ways in which stated choice models can be used to evaluate alternative recreation policies. Specifically, the authors state that one of the strengths of choice models is their predictive ability. That is, choice models provide recreation managers with foresight about how the public is likely to respond to various policy alternatives. Further, choice models provide managers with information about people's preferences for arrangements of resources, facilities, and/or services that may not currently exist.

There is a growing body of literature describing the application of stated choice analysis to outdoor recreation management issues in parks and related areas (Louviere \& Timmermans, 1990b; Louviere \& Woodworth, 1985; Schroeder, Dwyer, Louviere, \& Anderson, 1990). Other natural resource related applications of stated choice analysis include studies of river flow management (Adamowicz, Louviere, \& Williams, 1994), tourism (Haider \& Ewing, 1990), recreational hunting (Boxall, Adamowicz, Swait, Williams, \& Louviere, 1996; Bullock, Elston, \& Chalmers, 1998; Mackenzie, 1993), hazardous waste facility siting (Opaluch, Swallow, Weaver, Wessells, \& Wichelns, 1993; Swallow, Weaver, Opaluch, \& Michelman, 1994), watershed management (Johnston, Swallow, \& Weaver, 1999), and wildlife management (Adamowicz, Boxall, Williams, \& Louviere, 1998).

\section{Study Methods}

\section{Selection of Attributes and Levels}

Wilderness areas are managed, in general, to provide visitors with opportunities to experience solitude in a relatively unmodified natural environment with few management restrictions and facilities (Merigliano, 1990). An expanding body of research is helping to identify resource, social, and managerial setting attributes that reflect these general management objectives and contribute to or detract from the quality of the wilderness recreation experience (Merigliano, 1990; Roggenbuck, Williams, \& Watson, 1993; Shindler \& Shelby, 1992; Whittaker, 1992). These attributes are commonly referred to in the recreation literature as indicators of quality.

Manning (1999b) summarizes the results of a number of studies that have focused on identifying potential indicators of quality. Based on a review of this literature, an initial list of potential study attributes was developed. Through consultation with park staff at Denali, this list was reduced to a set of six wilderness setting attributes selected to define the social, resource, and management conditions of the Denali wilderness setting profiles. Attributes selected to reflect the social conditions of the Denali wilderness included the number of other groups encountered per day while hiking, and the likelihood of being able to camp out of sight and sound of other groups. Two attributes related to the resource conditions of the Denali wilderness were selected: the presence/extent of trails, and the amount of human impact at camping sites. The intensity of restrictions regarding where wilderness visitors are allowed to camp, and the level of difficulty of obtaining a permit for an overnight wilderness trip were selected as attributes to reflect the management conditions of the Denali wilderness.

A focus group was conducted prior to administration of the survey to determine whether individuals would have difficulty choosing between alternative wilderness settings defined by six attributes. Half of the focus group participants were given surveys with wilderness setting alternatives defined by three attributes, and half of the participants were given surveys with wilderness setting alternatives described by six attributes. Focus group participants indicated that they did not have difficulty evaluating wilderness settings composed of six 
TABLE 1 Denali Wilderness Setting Attributes and Levels

Social conditions

Number of other groups encountered per day while hiking:

Encounter 0 other groups per day while hiking

Encounter up to 2 other groups per day while hiking

Encounter up to 4 other groups per day while hiking

Opportunity to camp out of sight and sound of other groups:

Able to camp out of sight and sound of other groups all nights

Able to camp out of sight and sound of other groups most nights

Able to camp out of sight and sound of other groups a minority of nights

Resource conditions

Extent and character of hiking trails:

Hiking is along intermittent, animal like trails

Hiking is along continuous single track trails developed from prior human use

Hiking is along continuous trails with multiple tracks developed from prior

human use

Signs of human use at camping sites:

Camping sites have little or no signs of human use

Camping sites have some signs of human use-light vegetation damage, a few moved rocks

Camping sites have extensive signs of human use-bare soil, many rocks moved for wind protection and cooking

Management conditions

Regulation of camping:

Allowed to camp in any zone on any night

Required to camp in specified zones

Required to camp in designated sites

Chance of receiving an overnight backcountry permit:

Most visitors are able to get a permit for their preferred trip

Most visitors are able to get a permit for at least their second choice trip

Only a minority of visitors are able to get a backcountry permit

setting attributes. Additionally, those participants that answered the survey with wilderness settings defined by three attributes stated that they would have been able to answer the questions if additional attributes were included. Based on the outcome of the focus group and the relevance of the six setting attributes to wilderness management in Denali, all six attributes were included in the study. Three levels were defined for each of the six wilderness setting attributes, based on recommendations from park staff. Table 1 lists the attributes and their corresponding levels used in the study.

\section{Experimental Design}

Given three levels of each of the six study attributes, a full factorial design would produce a total of $3^{6}$ (729) hypothetical Denali wilderness settings. This number of alternatives is far too large to consider reasonably. Therefore, an orthogonal fractional factorial design was constructed containing 36 paired comparisons blocked into four questionnaire versions, each containing nine pairwise comparisons ${ }^{3}$ (Seiden, 1954). For a discussion of the use of fractional factorial designs in decision research, refer to Green and Srinivasan (1978). An example of a representative Denali wilderness setting comparison is presented in Figure 1. 


\section{Backcountry Setting A}

- Encounter up to 2 other groups per day while hiking.

- Able to camp out of sight and sound of other groups all nights.

- Hiking is along continuous, single track trails developed from prior human use.

- Camping sites have some signs of human use - light vegetation damage, a few moved rocks.

- Required to camp at designated sites.

- Only a minority of visitors are able to get a backcountry permit.
Backcountry Setting B

- Encounter up to 4 other groups per day while hiking.

- Able to camp out of sight and sound of other groups most nights.

- Hiking is along intermittent, animallike trails.

- Camping sites have some signs of human use - light vegetation damage, a few moved rocks.

- Required to camp at designated sites.

- Most visitors are able to get a backcountry permit for their preferred trip.

FIGURE 1 Example Denali wilderness setting comparison.

\section{Survey Administration}

Overnight wilderness visitors in Denali are required to obtain a permit and a bear resistant food container from the Visitor Center prior to their backpacking trip. The stated choice analysis survey was administered to overnight wilderness visitors at the Visitor Center when they returned the bear resistant food container at the end of their backpacking trip. The survey was administered from July 24 through September 2, 2000. The choice experiment was conducted as part of a larger study of Denali overnight wilderness visitors. Individuals who did not participate in other parts of the larger study were recruited for the stated choice study. Study participants were randomly assigned to complete one of four versions of the questionnaire on a laptop computer. In each of the nine choice questions included in each version of the questionnaire, respondents were asked to read through each setting description (A and B) and indicate which they preferred. The response rate for the stated choice analysis survey was $81.2 \%$, resulting in a total of 311 completed questionnaires (approximately 78 respondents for each version of the questionnaire) and 2,799 pairwise comparisons. Based on the conventional assumption in stated choice studies that responses are independent among and across respondents, the 2,799 comparisons are aggregated for data analysis.

\section{Data Coding}

Effects coding was used to represent the wilderness setting attributes in the statistical model. Similar to dummy coding, effects coding requires that one level of the variable 
TABLE 2 Effects Coding

\begin{tabular}{lcr}
\hline $\begin{array}{c}\text { Level of attribute } \\
\text { (e.g., Number of groups encountered } \\
\text { per day while hiking) }\end{array}$ & $\begin{array}{c}\text { First } \\
\text { indicator variable }\end{array}$ & $\begin{array}{c}\text { Second } \\
\text { indicator variable }\end{array}$ \\
\hline 0 other groups (baseline level) & -1 & -1 \\
Up to 2 other groups & 1 & 0 \\
Up to 4 other groups & 0 & 1 \\
\hline
\end{tabular}

(i.e., each wilderness setting attribute) be selected as the baseline or excluded level, so that the statistical model is not overidentified. For this study, the first level of each wilderness setting attribute was selected as the excluded level (e.g., " 0 other groups" for the "Number of other groups encountered per day while hiking" attribute). As a result, each wilderness setting attribute was represented in the statistical model by two indicator variables, one associated with the intermediate level of the attribute (e.g., "Up to 2 other groups" for the "Number of other groups encountered per day while hiking" attribute) and one associated with the third level of the attribute (e.g., "Up to 4 other groups" for the "Number of other groups encountered per day while hiking" attribute). To code for the first level of an attribute, both indicator variables were assigned values of -1 . To code for the second or intermediate level of the attribute, the indicator variable for the intermediate level of the attribute was coded 1 and the indicator variable for the third level was coded 0 . To code for the third level of the attribute, the indicator variable for the intermediate level of the attribute was coded 0 and the indicator variable for the third level was coded 1 (Boxall, Adamowicz, Swait, Williams, \& Louviere, 1996). The effects coding scheme used in this study is presented in Table 2.

The result of effects coding is that the coefficients on the indicator variables represent the ordinal utility (or disutility if the coefficient is negative) associated with the corresponding level of the attribute. The ordinal utility (or disutility) of the first level of the attribute is equal to the negative sum of the coefficients on the indicator variables corresponding to the attribute. The advantages of using effects coding rather than dummy codes are discussed in Adamowicz, Louviere, and Williams (1994), Boxall, Adamowicz, Swait, Williams, and Louviere (1996), and Louviere (1988).

\section{Study Findings}

The responses to the stated choice questions were analyzed using logistic regression analysis to estimate a linear utility difference function (Hosmer \& Lemeshow, 2000; Opaluch, Swallow, Weaver, Wessells, \& Wichelns, 1993). The coefficients of the utility difference function corresponding to the Denali wilderness setting attributes, together with their standard errors, Wald Chi-Square values, and $\mathrm{P}$ values are presented in Table 3. All coefficients are significantly different than zero at the $<.001 \%$ level, except the coefficients on "Up to 2 other groups" and "Intermittent animal like trails." The overall fit of the model is supported by the results of the Hosmer and Lemeshow goodness of fit test $\left(\chi^{2}=3.492, p=0.836\right)$.

The magnitude of significant coefficients reflects the relative importance of the corresponding level of the attribute to Denali overnight wilderness visitors. The values of the coefficients in Table 3 imply that signs of human use at campsites influence Denali overnight wilderness visitors' utility or satisfaction more than any other wilderness setting attribute considered in this study. Specifically, camping site conditions characterized as having "Extensive signs of human use" are evaluated less favorably by Denali overnight 
TABLE 3 Coefficient Estimates for Wilderness Setting Attributes

\begin{tabular}{|c|c|c|c|c|}
\hline Variable & Coefficient & $\begin{array}{l}\text { Standard } \\
\text { error }\end{array}$ & $\begin{array}{c}\text { Wald } \\
\text { Chi-Square }\end{array}$ & $\mathrm{P}$ value \\
\hline \multicolumn{5}{|c|}{ Encounters with other groups per day while hiking: } \\
\hline 0 other groups & $0.440^{*}$ & - & - & - \\
\hline Up to 2 other groups & 0.065 & 0.043 & 2.246 & 0.134 \\
\hline Up to 4 other groups & -0.504 & 0.044 & 132.826 & $<0.001$ \\
\hline \multicolumn{5}{|c|}{ Able to camp out of sight and sound of other groups: } \\
\hline All nights & $0.295^{*}$ & - & - & - \\
\hline Most nights & 0.145 & 0.044 & 11.148 & $<0.001$ \\
\hline A minority of nights & -0.440 & 0.045 & 94.814 & $<0.001$ \\
\hline \multicolumn{5}{|l|}{ Hiking is along: } \\
\hline Intermittent, animal like trails & $0.319^{*}$ & - & - & - \\
\hline $\begin{array}{l}\text { Single track trails developed from } \\
\text { human use }\end{array}$ & -0.028 & 0.044 & 0.403 & 0.526 \\
\hline $\begin{array}{l}\text { Multiple track trails developed } \\
\text { from human use }\end{array}$ & -0.291 & 0.043 & 46.340 & $<0.001$ \\
\hline \multicolumn{5}{|l|}{ Camping sites have: } \\
\hline Little or no signs of human use & $0.582^{*}$ & - & - & - \\
\hline Some signs of human use & 0.207 & 0.044 & 22.151 & $<0.001$ \\
\hline Extensive signs of human use & -0.790 & 0.049 & 264.972 & $<0.001$ \\
\hline \multicolumn{5}{|l|}{ Regulation of camping: } \\
\hline $\begin{array}{l}\text { Allowed to camp in any zone } \\
\text { on any night }\end{array}$ & $0.072^{*}$ & - & - & - \\
\hline Required to camp in specified zones & 0.140 & 0.048 & 8.620 & 0.003 \\
\hline Required to camp in designated sites & -0.212 & 0.045 & 21.948 & $<0.001$ \\
\hline \multicolumn{5}{|l|}{ Chance visitors have of receiving a permit: } \\
\hline Most get a permit for their preferred trip & $0.073^{*}$ & - & - & - \\
\hline $\begin{array}{l}\text { Most get a permit for at least their } \\
\text { second choice }\end{array}$ & 0.143 & 0.044 & 10.424 & 0.001 \\
\hline Only a minority get a permit & -0.216 & 0.043 & 24.656 & $<0.001$ \\
\hline
\end{tabular}

*Coefficients for the excluded level of the attribute were not estimated by the statistical model. They were calculated as the negative sum of the coefficients on the other two levels of the corresponding attribute.

wilderness visitors than any other level of the six wilderness setting attributes studied. Additionally, camping site conditions characterized by "Little or no signs of human use" are preferred more than any level of any other wilderness setting attribute included in the study.

The magnitude of the coefficient estimates in Table 3 indicates that solitude-related attributes represent a second tier of importance to Denali overnight wilderness visitors. That is, while the number of encounters with other groups per day while hiking and opportunities to camp out of sight and sound of other groups are less important wilderness setting attributes relative to campsite impacts, they demonstrate a relatively large influence on Denali overnight wilderness visitors' utility. The extent and character of trails, regulations concerning where visitors are allowed to camp in the Denali wilderness, and the availability of backcountry permits are less important to Denali overnight wilderness visitors, relative to campsite impacts and solitude-related attributes of the Denali wilderness. 
The relationship between the levels of each wilderness setting attribute and the average utility associated with all possible combinations of the six Denali wilderness setting attributes are plotted in Figures $2 \mathrm{a}-2 \mathrm{f}$. The values on the $\mathrm{x}$-axis of each plot represent the level of the corresponding Denali wilderness setting attribute, and the values on the y-axis represent the amount by which the utility of the corresponding level of the attribute deviates from average utility or satisfaction. The values on the y-axis are expressed in units of utility, which is a measure of relative preference. Levels of attributes with high utility values are preferred to levels of attributes with lower utility values. The plots provide further graphic insight into the relative importance of the wilderness setting attributes to Denali overnight wilderness visitors. For example, utility drops sharply as campsites change from having "Some signs of human use" $(+0.207)$ to "Extensive signs of human use" $(-0.790)$ (Figure 2d), whereas the loss of utility is less dramatic as the opportunity to camp out of sight and sound of other groups changes from "All nights" (0.295) to "Most nights" (0.145) (Figure 2b). ${ }^{4}$

The results of the stated choice experiment suggest that Denali overnight wilderness visitors support some level of management over where visitors may camp and a certain degree of visitor use limits. Denali overnight wilderness visitors' utility remains unchanged as regulations over where visitors may camp increases from "Allowed to camp in any zone on any night" to "Required to camp in specified zones" (Figure 2e). However, utility decreases to its lowest point with respect to camping regulations when visitors are "Required to camp in designated sites." A similar trend is observed concerning overnight wilderness use limits. Denali overnight wilderness visitors' utility associated with this attribute is statistically the same whether use limits are at their least restrictive level (i.e., "Most get a permit for their preferred trip") or at the intermediate level (i.e., "Most get a permit for at least their second choice trip") (Figure 2e). Use limits that result in only a minority of visitors receiving a permit lead to the lowest utility related to use limits (i.e., the chance visitors have of receiving a permit). A possible explanation for these results is that Denali overnight wilderness visitors may realize that without certain management restrictions, the resource and social setting attributes of the Denali wilderness are likely to deteriorate beyond acceptable conditions.

An additional use of the model developed in this study is to predict the preferences of Denali overnight wilderness visitors for alternative wilderness management scenarios. As an example, two hypothetical Denali wilderness management alternatives will be considered. The first alternative will be referred to as the "Solitude Alternative" and the second alternative the "Freedom Alternative." Under the "Solitude Alternative," overnight wilderness visitors would encounter zero other groups per day while hiking and be able to camp out of sight and sound of other groups all nights. However, the two management attributes would be at their most restrictive levels. That is, visitors would be required to camp in designated sites and only a minority of visitors would be able to get a backcountry permit. Under the "Freedom Alternative," overnight wilderness visitors would be able to camp in any zone on any night, and most visitors would be able to get a permit for their preferred trip. However, visitors would encounter up to four other groups per day while hiking, and they would be able to camp out of sight and sound of other groups only a minority of nights. In both alternatives, the extent of social trails and the amount of impact to campsites would be fixed at the intermediate level. At the heart of the comparison between the "Solitude Alternative" and the "Freedom Alternative" are Denali overnight wilderness visitors' evaluations of the tradeoff between freedom of access to the Denali wilderness and the opportunity to experience solitude.

The maximum likelihood coefficients and the effects codes corresponding to the levels of the six wilderness setting attributes for each hypothetical alternative are presented in Table $4 .{ }^{5}$ The model predicts that in a hypothetical referendum, $75 \%$ of Denali overnight 

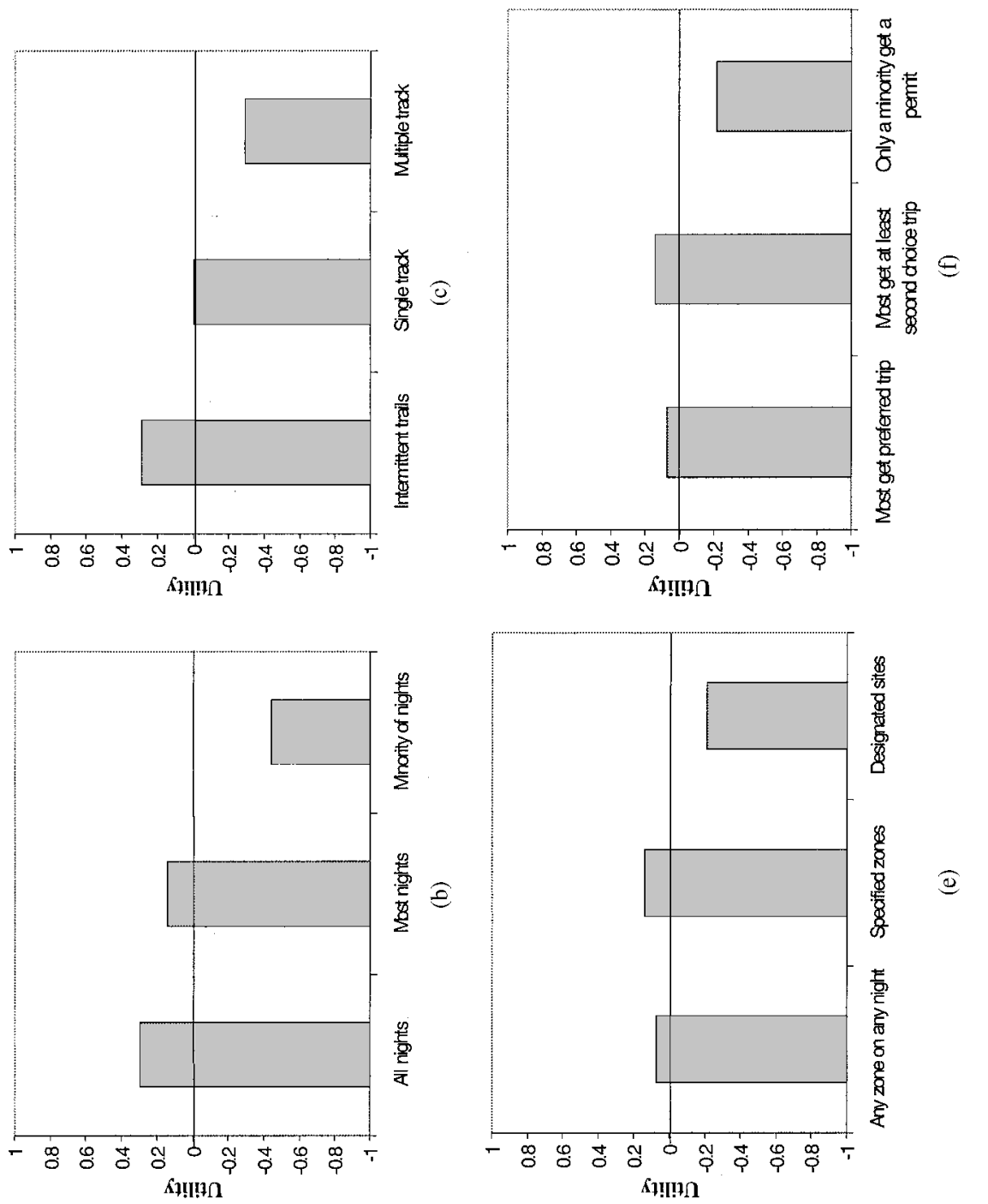

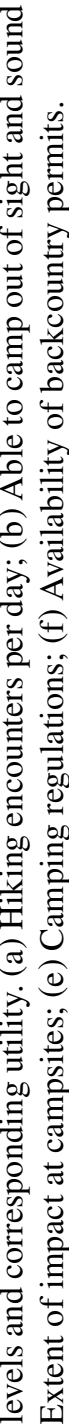
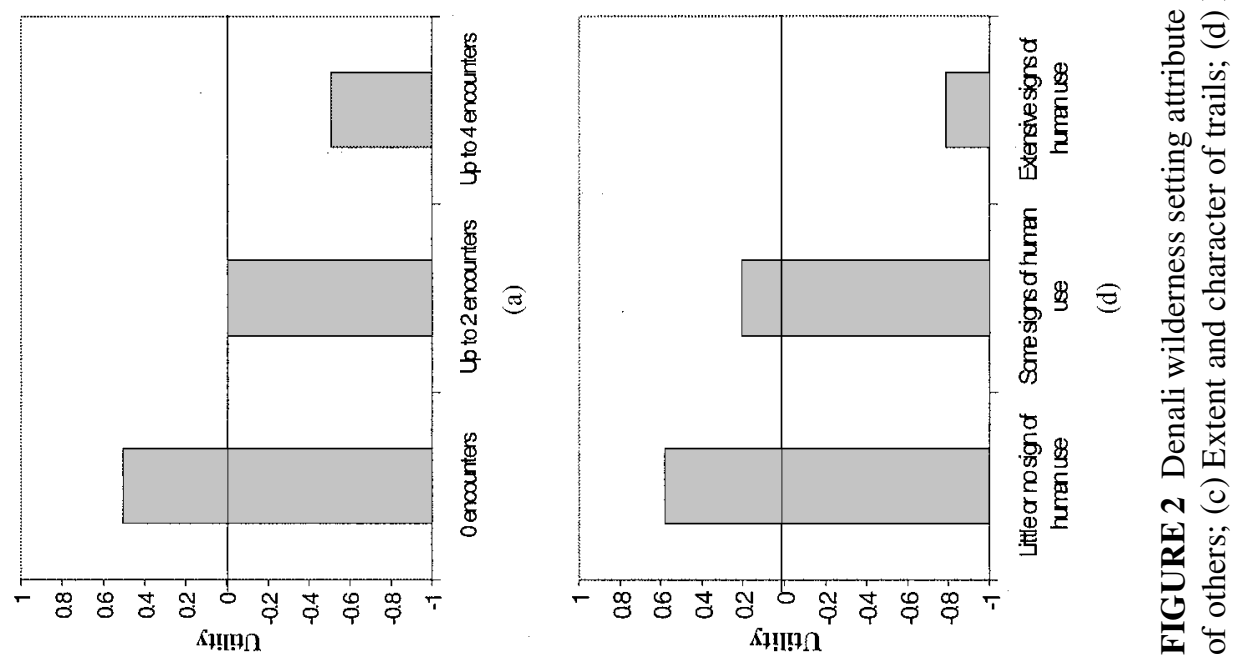
wilderness visitors would choose the "Solitude Alternative" and only $25 \%$ would choose the "Freedom Alternative." This result implies that, in general, Denali overnight wilderness visitors would prefer to forgo some freedom from management to improve opportunities to experience solitude. These findings are suggestive of the balance overnight wilderness visitors think ought to be struck among the conditions of social, resource, and managerial attributes of the Denali wilderness experience. In the context of this example, if Denali wilderness managers choose a balance of tradeoffs more consistent with the "Freedom Alternative," they may receive less public support for their management actions as a consequence.

TABLE 4 Scores for Two Hypothetical Denali Wilderness Management Alternatives

Solitude Attribute Freedom Attribute

Variable Coefficient alternative scores alternative scores

Encounters with other groups per day while hiking:

0 other groups

Up to 2 other groups

$\begin{array}{rr}0.440^{*} & - \\ 0.065 & -1 \\ -0.504 & -1\end{array}$

$-0.065$

$\overline{0}$

- 0

Up to 4 other groups

$-0.504$

0.504

$-0.504$

Able to camp out of sight and sound of other groups:

All nights

Most nights

A minority of nights

Hiking is along:

Intermittent, animal like trails

Single track trails developed from human use

Multiple track trails developed $\quad-0.291$ from human use

Camping sites have:

Little or no signs of human use

Some signs of human use

$0.295^{*}-$

0.145

$-0.440$

$-1$

$-1$

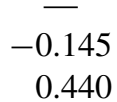

$\overline{0}$

0

$-0.440$

$$
0.319^{*}
$$

$-0.028$

$-$

$-\overline{0.028}$

$\overline{1}$

$-0.028$

Extensive signs of human use

Regulation of camping:

Allowed to camp in any zone on any night

Required to camp in specified zones

Required to camp in designated sites

$0.582^{*}$
0.207
-0.790

1

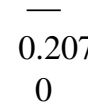

$0.072 *$

0.140

0

0

$-1$

$-0.140$

$-0.212$

1

$-0.212$

$-1$

0.212

Chance visitors have of receiving a permit:

Most get a permit for their preferred trip

Most get a permit for at least

$0.073^{*}$

their second choice

Only a minority get a permit $\quad-0.216$

Cumulative score

$$
0.143
$$

Voting proportion

${ }^{*}$ Coefficients for the excluded level of each attribute are not used in the calculation of management alternative scores. 


\section{Discussion and Conclusions}

In this study, stated choice analysis has been used to integrate consideration of the conditions of social, resource, and managerial attributes of the Denali wilderness into decisions about how to manage the park's wilderness. The results of the stated choice analysis presented in this article have several potential implications for the normative approach to recreation research and for formulating indicators and standards of quality for wilderness management at Denali and elsewhere.

Study findings provide Denali wilderness managers with information about the relative importance that overnight wilderness visitors place on the attributes of the Denali wilderness experience selected for this study. For example, study results suggest that visitors would be willing to tolerate, and in fact support, management restrictions, including use limits, to achieve desired social and resource setting attribute conditions. These findings are potentially more consistent with normative theory than information developed using conventional normative approaches to assist managers in selecting and prioritizing indicators of quality. Specifically, information concerning the relative importance of the attributes included in this study reflects how visitors think managers ought to prioritize the conditions of the study attributes, given the relationships and inherent tradeoffs among these attributes.

The results of this study indicate that certain levels of each of the six Denali wilderness setting attributes provide a greater than average level of utility to Denali overnight wilderness visitors. Moreover, Figures $2 \mathrm{a}-2 \mathrm{f}$ illustrate that when the levels of the Denali wilderness setting attributes deteriorate beyond certain "thresholds" (e.g., when camping sites deteriorate from having some signs of human use to extensive signs of human use), they provide less than average levels of utility. These findings imply that the wilderness experience can be protected from substantial decline by keeping wilderness setting conditions from deteriorating beyond such "threshold" levels. Likewise, the wilderness experience in Denali can be substantially improved by restoring social, resource, and management conditions of the wilderness from below "threshold" levels.

The threshold levels for each of the six Denali wilderness setting attributes, illustrated in Figures $2 \mathrm{a}-2 \mathrm{f}$, could be used by park managers to help formulate standards of quality. In effect, these figures are analogous to "norm curves" generated in conventional normative research. For example, Figure 2 a demonstrates that fewer than two encounters with other groups per day while hiking provides a greater than average level of utility to Denali overnight visitors and that encounters with more than two other groups per day while hiking provides a less than average level of utility. Therefore, a potential standard of quality for this attribute might be set at "up to 2 encounters with other groups per day while hiking." The use of stated choice analysis data to help formulate standards of quality for wilderness setting conditions represents a potential improvement to the conventional normative approach in recreation research because resulting data are derived from a more holistic or contextual perspective. That is, visitors' normative judgments and the resulting statistical analysis reflect what visitors think ought to be, given the inherent tradeoffs among the conditions of social, resource, and managerial attributes of the Denali wilderness experience. Further, this expanded approach to normative research yields information to help formulate standards of quality for multiple and related wilderness attributes simultaneously.

The decision-making model developed in this study allows managers to evaluate Denali overnight wilderness visitors' attitudes toward alternative management scenarios. This allows managers to consider combinations of setting attributes that are not currently in place, but may offer a better alternative than the status quo. Additionally, alternatives being considered under the new wilderness management plan can be generalized to the model, and managers can predict the response of current users to each alternative. The results of 
the example application of the choice model provide evidence that visitors are willing to trade-off freedom from management restrictions for desired social conditions. Specifically, the results demonstrate that in a hypothetical referendum, Denali overnight wilderness visitors would prefer (by a margin of three to one) a wilderness setting that emphasizes solitude through relatively restrictive management actions over a more congested wilderness setting with limited management restrictions.

From a management perspective, these results suggests that the majority of Denali overnight wilderness visitors support backcountry permit quotas at Denali to protect the primitive character of the wilderness. Further, the results suggest that a moderately restrictive quota system that is designed to enhance overnight wilderness visitors' opportunities to experience solitude and to maintain relatively undisturbed campsite and trail conditions will receive the greatest support from Denali overnight wilderness visitors. However, the results of the example application of the choice model suggest that there is also a substantial proportion of Denali overnight wilderness visitors $(25.0 \%)$ that place high importance on freedom from management restrictions despite reduced opportunities to experience limited contact with other groups while hiking and camping. This finding suggests that Denali overnight wilderness visitors are at least somewhat diverse in their attitudes concerning the management of the Denali wilderness. Park managers could address this diversity through management of the Denali wilderness based on the concept of zoning to provide a spectrum of opportunities for visitors. For example, the quota system could be designed in such a way that quotas for most zones within the Denali wilderness are set at levels that emphasize opportunities for visitors to experience solitude, while quotas for a few zones of the wilderness are set at levels that provide greater visitor access.

Stated choice analysis shows promise as a tool to supplement and extend the normative approach to recreation research. By asking respondents to consider the tradeoffs associated with wilderness management, stated choice analysis may be more capable of explicitly addressing the "oughtness" of wilderness management than would be conventional normative approaches. The normative judgments derived from stated choice analysis concerning how visitors think the tradeoffs inherent in park and wilderness management ought to be balanced have the potential to make the complex and often controversial decisions managers face more tractable.

\section{Notes}

1. Decision making models developed using stated choice analysis are based on the theoretical framework of random utility. Refer to Hanemann (1984) and Opaluch, Swallow, Weaver, Wessells, and Wichelns (1993) for detailed presentations of the random utility framework.

2. Stated preference methods, including conjoint analysis, are related to stated choice methods, and are also used to evaluate public preferences for multiple attribute goods. Respondents to conjoint analysis studies are asked to rate or rank alternatives, rather than choose among alternatives. For a detailed discussion of conjoint ranking see Dennis (1998) and Mackenzie (1993). For a detailed discussion of conjoint rating see Mackenzie (1993), Stevens, Belkner, Dennis, Kittredge, and Willis (2000), and Teisl, Boyle, and Roe (1996).

3. The orthogonal fractional factorial design was constructed by Don Anderson of StatDesign Consulting, Evergreen, Colorado.

4. To test whether differences in utility associated with changes in the level of an attribute are significantly different than zero (e.g., the change in utility associated with a change in the opportunity to camp out of sight and sound of other groups from "All nights" to "Most nights"), two additional logistic regression analyses were performed. In the two additional analyses the wilderness setting attributes were represented in the statistical model using dummy coding rather than effects coding. Results of the additional analyses indicate that the difference in utility associated with being "Allowed 
to camp in any zone on any night" versus being "Required to camp in specified zones," and the difference in utility associated with "Most visitors are able to get a permit for their preferred trip" versus "Most visitors are able to get a permit for at least their second choice trip" are not significantly different than zero. All other utility differences associated with different levels of the attributes were found to be significantly different than zero.

5. Refer to Opaluch, Swallow, Weaver, Wessells, and Wichelns (1993) for a presentation of the methods used to calculate scores for the hypothetical management alternatives.

\section{References}

Adamowicz, W., Boxall, P., Williams, M., \& Louviere, J. (1998). Stated preference approaches for measuring passive use values: Choice experiments and contingent valuation. American Journal of Agricultural Economics, 80, 64-75.

Adamowicz, W., Louviere, J., \& Williams, M. (1994). Combining revealed and stated preference methods for valuing environmental amenities. Journal of Environmental Economics and Management, 26, 271-292.

Boxall, P., Adamowicz, W., Swait, J., Williams, M., \& Louviere, J. (1996). A comparison of stated preference methods for environmental valuation. Ecological Economics, 18, 243253.

Bullock, C., Elston, D., \& Chalmers, N. (1998). An application of economic choice experiments to a traditional land use-Deer hunting and landscape change in the Scottish Highlands. Journal of Environmental Management, 52, 335-351.

Bultena, G., Albrecht, D., \& Womble, P. (1981). Freedom versus control: A study of backpackers' preferences for wilderness management. Leisure Sciences, 4(3), 297-310.

Dennis, D. (1998). Analyzing public inputs to multiple objective decisions on national forests using conjoint analysis. Forest Science, 44(3), 421-429.

Green, P., \& Srinivasan, V. (1978). Conjoint analysis in consumer research: Issues and outlook. Journal of Consumer Research, 5, 103-123.

Haider, W., \& Ewing, G. (1990). A model of tourist choices of hypothetical Caribbean destinations. Leisure Sciences, 12, 33-47.

Hall, T. (In Press). Use limits in wilderness. In W. Freimund \& D. Cole (Comps.), 2001. Social density and wilderness experiences; 2000 June 1-3; Missoula, MT. Proceedings. Ogden, UT: USDA, Forest Service, Rocky Mountain Research Station.

Hall, T., \& Shelby, B. (1996). Who cares about encounters? Differences between those with and without norms. Leisure Sciences, 18(1), 7-22.

Hanemann, W. (1984). Welfare evaluations in contingent valuation experiments with discrete responses. American Journal of Agricultural Economics, 66, 332-341.

Hendee, J., Stankey, G., \& Lucas, R. (1990). Wilderness management. Golden, CO: North American Press.

Hosmer, D., \& Lemeshow, S. (2000). Applied logistic regression. New York, NY: John Wiley \& Sons.

Johnston, R., Swallow, S., \& Weaver, T. (1999). Estimating willingness to pay and resource tradeoffs with different payment mechanisms: An evaluation of a funding guarantee for watershed management. Journal of Environmental Economics and Management, 38, 97120.

Lawson, S., \& Manning, R. (2000a). Crowding versus access at Delicate Arch, Arches National Park: An indifference curve analysis. Proceedings of the Third Symposium on Social Aspects and Recreation Research.

Lawson, S., \& Manning, R. (2000b). Evaluating multiple dimensions of visitors' tradeoffs between access and crowding at Arches National Park using indifference curve analysis. Proceedings of the Third Symposium on Social Aspects and Recreation Research.

Lawson, S., \& Manning, R. (2001). Solitude versus access: A study of tradeoffs in outdoor recreation using indifference curve analysis. Leisure Sciences, 23(3), 179-191. 
Louviere, J. (1988). Analyzing decision making: Metric conjoint analysis. Newbury Park: Sage Publications.

Louviere, J., \& Timmermans, H. (1990a). Stated preference and choice models applied to recreation research: A review. Leisure Sciences, 12, 9-32.

Louviere, J., \& Timmermans, H. (1990b). Using hierarchical information integration to model consumer responses to possible planning actions: Recreation destination choice illustration. Environment and Planning, 22, 291-308.

Louviere, J., \& Woodworth, G. (1985). Models of park choice derived from experimental and observational data: A case study in Johnston County, Iowa. University of Iowa, Iowa City Technical Report.

Mackenzie, J. (1993). A comparison of contingent preference models. American Journal of Agricultural Economics, 75, 593-603.

Manning, R. (1999a). Crowding and carrying capacity in outdoor recreation: From normative standards to standards of quality. In Leisure studies for the twenty-first century (pp. 323-334). State College, PA: Venture Press.

Manning, R. (1999b). Studies in outdoor recreation: Search and research for satisfaction. Corvallis, OR: Oregon State University Press.

Manning, R., Lime, D., Freimund, W., \& Pitt, D. (1996). Crowding norms at frontcountry sites: A visual approach to setting standards of quality. Leisure Sciences, 18(1), 39-59.

Manning, R., Lime, D., \& Hof, M. (1996). Social carrying capacity of natural areas: Theory and application in the national parks. National Areas Journal, 16(2), 118-127.

Manning, R., Valliere, W., Wang, B., \& Jacobi, C. (1999). Crowding norms: Alternative measurement approaches. Leisure Sciences, 21(2), 97-115.

Merigliano, L. (1990). Indicators to monitor the wilderness recreation experience. In Managing America's enduring wilderness resource (156-162). St. Paul, MN: University of Minnesota.

Opaluch, J., Swallow, S., Weaver, T., Wessells, C., \& Wichelns, D. (1993). Evaluating impacts from noxious facilities: Including public preferences in current siting mechanisms. Journal of Environmental Economics and Management, 24, 41-59.

Roggenbuck, J., Williams, D., \& Watson, A. (1993). Defining acceptable conditions in wilderness. Environmental Management, 17(2), 187-197.

Schroeder, H., Dwyer, J., Louviere, J., \& Anderson, D. (1990). Monetary and nonmonetary trade-offs of urban forest site attributes in a logit model of recreation choice. General Technical Report-US Department of Agriculture, Forest Service, RM-197, 41-51.

Seiden, E. (1954). On the problem of construction of orthogonal arrays. Annals of Mathematical Statistics, 25, 151-156.

Shelby, B., Vaske, J., \& Harris, R. (1988). User standards for ecological impacts at wilderness campsites. Journal of Leisure Research, 20(3), 245-256.

Shelby, B., \& Whittaker, D. (1990). Recreation values and instream flow needs on the Delores River. Paper presented at the Third Conference on Society and Resource Management, College Station, TX.

Shindler, B., \& Shelby, B. (1992). User assessment of ecological and social campsite attributes. Defining wilderness quality: The role of standards in wilderness management $-A$ workshop proceedings. USDA Forest Service General Technical Report PNW-305, 107-114.

Stevens, T., Belkner, R., Dennis, D., Kittredge, D., \& Willis, C. (2000). Comparison of contingent valuation and conjoint analysis in ecosystem management. Ecological Economics, 32, 6374.

Swallow, S., Weaver, T., Opaluch, J., \& Michelman, T. (1994). Heterogeneous preferences and aggregation in environmental policy analysis: A landfill siting case. American Journal of Agricultural Economics, 76, 431-443.

Teisl, M., Boyle, K., \& Roe, B. (1996). Conjoint analysis of angler evaluations of Atlantic salmon restoration on the Penobscot River, Maine. North American Journal of Fisheries Management, $16,861-871$.

Vaske, J., \& Donnelly, M. (1988). Normative evaluations of wildlife management. Paper presented at the Annual Congress of the National Recreation and Park Association, Indianapolis, IN. 
Whittaker, D. (1992). Selecting indicators: Which impacts matter more? Defining wilderness quality: The role of standards in wilderness management $-A$ workshop proceedings. USDA Forest Service General Technical Report PNW-305, 13-22.

Williams, D., Roggenbuck, J., \& Bange, S. (1991). The effect of norm-encounter compatibility on crowding perceptions, experience, and behavior in river recreation settings. Journal of Leisure Research, 23, 154-172. 
Copyright of Leisure Sciences is the property of Taylor \& Francis Ltd and its content may not be copied or emailed to multiple sites or posted to a listserv without the copyright holder's express written permission. However, users may print, download, or email articles for individual use. 